\title{
Sentimentos vivenciados na oxigenoterapia hiperbárica: a voz dos usuários
}

\author{
Feelings experienced in hyperbaric oxygen therapy: the users' voice
}

\author{
Sentimientos vividos en la oxigenoterapia hiperbárica: una voz de los usuarios
}

Maria Samya Carvalho Machado1,2, Evanilda Souza de Santana Carvalho3, Rayssa Fagundes Batista Paranhos, ${ }^{4,}$, Cintia Silva de Souza Costa ${ }^{5}$

\section{ORCID IDS}

Machado MSC (D) https://orcid.org/0000-0002-4336-3827

Carvalho ESS (D) https://orcid.org/0000-0003-4564-0768

Paranhos RFB (D) https://orcid.org/0000-0002-7690-6453

Costa CSS (D) https://orcid.org/0000-0002-5814-8433

\section{COMO CITAR}

Machado MSC; Carvalho ESS; Paranhos RFB; Costa CSS. Sentimentos vivenciados na oxigenoterapia hiperbárica: a voz dos usuários. ESTIMA, Braz. J. Enterostomal Ther., 2020, 18: e1920. https://doi. org/10.30886/estima.v18.860_PT

\begin{abstract}
RESUMO
Objetivo: Caracterizar os sentimentos vivenciados pelos usuários da oxigenoterapia hiperbárica (OHB). Métodos: Estudo qualitativo, utilizando técnicas multiparamétricas para coleta de dados como a técnica de associação livre de palavras, procedimento desenhoestória com tema e a entrevista semiestruturada. Para a análise, o material discursivo, juntamente com a visualização dos desenhos e as respostas das associações livres de palavras, foi cruzado e empregado o método de análise de conteúdo permitindo, dessa forma, retratar os sentimentos vivenciados na OHB. Resultados: Emergiram as categorias: medo e ansiedade; sentimento de prisão e cansaço; felicidade e confiança/esperança, sendo que esta última subdividida em confiança na terapia e em Deus. Conclusão: Após as primeiras sessões e principalmente após as orientações e incentivos dos profissionais, os sentimentos negativos foram amenizados e cederam espaço para a satisfação, seguidos de felicidade em poder voltar ao convívio familiar e social e tudo isso ancorado no sentimento de esperança e fé.
\end{abstract}

DESCRITORES: Cuidados de enfermagem; Oxigenação hiperbárica; Emoções; Pesquisa qualitativa; Estomaterapia.

\begin{abstract}
Objective: To characterize the feelings experienced by users of hyperbaric oxygen therapy (HBOT). Methods: Qualitative study, using multiparametric techniques for data collection such as the free word association technique, drawing-and-story procedure with theme and the semistructured interview. For the analysis, the discursive material, together with the visualization of the drawings and the responses of the word-free associations, was cross-referenced and the method of content analysis was employed, thus allowing the feelings experienced at HBOT to be portrayed. Results: The categories emerged: fear and anxiety; feeling of imprisonment and tiredness; happiness and confidence/hope, the latter being subdivided into trust in the therapy and in God. Conclusion: After, the first sessions and especially after the guidance and incentives from the professionals, the negative feelings were softened and gave way to satisfaction, followed by happiness in being able to return to family and social life and all this anchored in the feeling of hope and faith.
\end{abstract}

DESCRIPTORS: Nursing care; Hyperbaric oxygenation; Emotions; Qualitative research; Enterostomal therapy.

\footnotetext{
1. Hospital Clériston Andrade - Feira de Santana (BA), Brasil.

2. Cliof Oftalmoogia - Feira de Santana (BA), Brasil.

3. Universidade Estadual Feira de Santana - Feira de Santana (BA), Brasil.

4. Estomaclin Serviços Médicos, enfermagem e estomaterapia - Salvador (BA), Brasil.

5. Hiperbárica Feira de Santana - Feira de Santana (BA), Brasil.

*Autora correspondente: rayssa.paranhos@gmail.com

Recebido: Mar. 12, 2020 | Aceito: Ago. 10, 2020
} 


\section{RESUMEN}

Objetivo: Objetivo: caracterizar las sensaciones que experimentan los usuarios de oxigenoterapia hiperbárica (OHB). Métodos: estudio cualitativo, uso de técnicas multiparamétricas para la recopilación de datos como técnica de asociación de palabras libre, procedimiento de dibujo-historia con tema y entrevista semiestructurada. Para el análisis, el material discursivo, junto con la visualización de los dibujos y las respuestas de las asociaciones de palabras libres, se cruzó y utilizó el método de análisis de contenido, manera, retrata los sentimientos experimentados en HBO. Resultados: Surgieron las categorías: miedo y ansiedad; sentimiento de prisión y cansancio; felicidad y confianza / esperanza, esta última subdividida en confianza en la terapia y en Dios. Conclusión: Después las primeras sesiones y principalmente después de la orientación e incentivos de los profesionales, se mitigaron los sentimientos negativos y dio paso a la satisfacción, seguida de la alegría de poder volver a la vida familiar y social y todo ello anclado en sentimiento de esperanza y fe.

DESCRIPTORES: Atención de Enfermería; Oxigenación hiperbárica; Emociones; Investigación cualitativa; Estomaterapia.

\section{INTRODUÇÃO}

A oxigenoterapia hiperbárica $(\mathrm{OHB})$ é uma terapêutica que oferece oxigênio em uma pureza superior a 99\% v/v (percentagem volúmica) em um ambiente com pressão superior à atmosférica entre 2 a 3 ATA (acima da tensão atmosférica) sendo habitualmente empregada 2,4-2,8 ATA por um período médio de 60 a 90 minutos. Esse ambiente é obtido dentro de uma câmara cuja aparência se assemelha à de um submarino, onde o paciente recebe uma máscara pela qual o oxigênio será administrado1. As indicações clínicas são diversas, vão desde problemas pulmonares, vasculares, isquêmicos e infecções, às feridas em pessoas com diabetes, lesões extensas como Fournier, queimaduras, radiodermites, entre outras. Os efeitos adversos estão relacionados à variação da pressão e à toxicidade ao oxigênio como tosse seca, desconforto nos seios da face, barotrauma auditivo, zumbido e, em raras exceções, edema pulmonar. As contraindicações são pneumotórax, fibrose, enfisema pulmonar e insuficiência cardíaca ${ }^{1,2}$.

A recomendação é a aplicação da OHB diariamente, entre 10 a 30 sessões consecutivas, sendo definida conforme indicação do médico hiperbaricista. A necessidade clínica de estar na câmara todos os dias associada ao convívio com uma doença que limita a vida levam a modificações no estilo de vida e geram sentimentos diversos.

A primeira sessão de OHB é um marco: o indivíduo, envolto em seus sentimentos e emoções que o acompanham durante todo o processo patológico, vê-se diante de uma possibilidade de cura mais rápida e eficaz, gerando em si os sentimentos de esperança, ansiedade e medo diante do desconhecido.

Sendo assim, cuidar das pessoas na $\mathrm{OHB}$ não envolve apenas a realização das sessões, mas abrange questões como crenças, percepções e significados. As emoções vivenciadas bem como os aspectos culturais não podem ser desconsideradas a fim de se alcançar um cuidado holístico e total adesão ao tratamento.

Os profissionais de saúde e estudantes de enfermagem envolvidos na assistência prestam cuidados técnicos para a execução das sessões, mas também se veem como agentes de transformação na escuta dos medos, das dúvidas e da incerteza do que pode ocorrer naquele ambiente, contribuindo para o sucesso da terapia. Durante esse atendimento, percebeu-se que essas pessoas precisavam ser ouvidas para o cuidado de enfermagem ser direcionado para as reais necessidade e não baseado no que a enfermagem acreditava como melhor. Nesse sentido, percebeu-se a necessidade de abrir um espaço de escuta terapêutica, surgindo algumas questões para refletir: quais são os sentimentos vivenciados pelos usuários da oxigenoterapia hiperbárica? Como se dá o processo de inserção desses indivíduos na terapia? E quais são suas expectativas face ao tratamento? Respondendo a esses questionamentos, definiu-se como objetivo caracterizar os sentimentos vivenciados pelos usuários da $\mathrm{OHB}$.

Este estudo oferece uma abordagem da oxigenoterapia hiperbárica, sob a perspectiva de quem a vivência - dos usuários que precisam dos cuidados da enfermagem na óptica de suas necessidades. Mesmo entendendo que o estudo possui limitações quanto ao número de sujeitos, foi possível fazer um levantamento dos sentimentos vivenciados, contribuindo para uma assistência de enfermagem voltada para as necessidades dos usuários e sua melhor adaptação ao tratamento.

\section{MÉTODO}

Pesquisa envolvendo 14 pessoas em tratamento com $\mathrm{OHB}$, maiores de 18 anos e que já tinham realizado pelo menos uma sessão de $\mathrm{OHB}$, tendo então a vivência 
do procedimento para poder relatar sua experiência. Os indivíduos com déficit cognitivo, cujo estado de saúde foi considerado crítico ou que não se sentiam confortáveis em responder às perguntas e participar das dinâmicas projetivas foram excluídos.

A aplicação desta pesquisa ocorreu em um centro de terapia hiperbárica, em uma cidade do interior da Bahia, que presta serviço às pessoas cadastradas no Sistema Único de Saúde (SUS), nos planos de saúde e através de consulta particular, provenientes de diversas cidades circunvizinhas.

A pesquisa qualitativa permite estudar a história, as relações, representações, crenças, percepções e opiniões, que as pessoas constroem a respeito da sua maneira de viver, pensar e sentir ${ }^{3}$. Por se tratar de um estudo onde, em que o foco principal são sentimentos, componentes subjetivos da consciência e do inconsciente do ser, de qualidade incontrolável e que não são acessados tão facilmente, foi aplicada uma abordagem de multimétodos ${ }^{4}$. Utilizaram-se duas técnicas projetivas: o teste da associação livre de palavras (TALP) e o procedimento desenho-estória com tema e, ao final, aplicou-se uma entrevista semiestruturada. Essas técnicas projetivas foram desenvolvidas na área da psicologia e têm sido utilizadas por outras áreas, como da saúde, para a elaboração de pesquisas com enfoque qualitativo. Por serem técnicas simples, que não requerem um empenho maior da cognição, podem ser utilizadas em crianças e pessoas com baixa escolaridade, sem prejuízo nas informações coletadas ${ }^{5}$.

O TALP consiste em o participante, após ouvir uma palavra ou frase, escrever ou falar outra palavra que lhe vem à mente. $\mathrm{O}$ entrevistador lança um estímulo indutor e espera a livre evocação verbal, guardada na memória do entrevistado ${ }^{4}$.

Para essa técnica, lançou-se duas frases como estímulo indutor: fale cinco palavras ou frases quando eu digo "hiperbárica" e fale cinco palavras ou frases quando eu digo "hiperbárica e eu”. Em seguida, as cinco palavras ou expressões evocadas pelo entrevistado foram registradas pela autora, obedecendo as ordens de aparição. A escolha dessa técnica permitiu o acesso espontâneo ao universo dos sentimentos das pessoas que utilizam a terapia hiperbárica, sem que eles sejam perdidos ou mascarados durante o processo de coleta.

Para assegurar que nenhuma palavra ou expressão fosse perdida durante a aplicação do TALP, foi utilizado um gravador para posteriormente confirmar as evocações registradas.

No segundo teste projetivo, procedimento desenhosestória com tema, solicita-se que a pessoa faça um desenho que represente aquele momento que está vivendo. Essa representação gráfica expressa os pensamentos e sentimentos da pessoa na $\mathrm{OHB}$ e, posteriormente, conta-se uma estória sobre o desenho com começo, meio e fim ${ }^{5}$. A entrevistadora grava a estória contada e, após o participante ouvi-la, solicita um título para ela. Para a aplicação dessa técnica, a pesquisadora disponibilizou ao participante papeis de ofício, lápis de cor, gizes de cera e canetas hidrográficas.

Para finalizar a coleta, utilizou-se a entrevista semiestruturada com finalidade de caracterizar o perfil dos participantes e relacionar as técnicas projetivas entre si e com a entrevista, cruzando as informações extraídas e fechando a coleta dos dados.

As entrevistas foram coletadas até que se obtivesse a saturação das respostas. $\mathrm{O}$ critério de saturação para coleta de dados refere-se à repetição de conteúdos semelhantes nas falas dos participantes sem surgimento de elementos novos e a confirmação da complementação entre o TALP e as explicações sobre os desenhos.

Os participantes foram orientados quanto às técnicas projetivas antes de se iniciar a coleta de dados e foram acompanhados pela profissional durante o preenchimento dos instrumentos, sanando as dúvidas ainda existentes.

Para a análise do conteúdo, utilizou-se uma abordagem com multitécnicas, possibilitando cruzamento de dados que permitiram retratar os sentimentos vivenciados na $\mathrm{OHB}$, adotando, dessa forma, o método de análise de conteúdo temático de Bardin para análise dos dados do procedimento de desenho-estória com tema. Para processar o TALP, compilaram-se as palavras ou frases que mais apareceram e se repetiram entre as entrevistas.

A análise dos desenhos-estória com tema abrange tratamento de material discursivo produzido pelas estórias, juntamente com a visualização de elementos gráficos construídos pelos participantes. Sob esse ponto de vista, estória e desenho se completam, possibilitando ao investigador acessar o contexto em que as experiências narradas foram produzidas ${ }^{5}$.

Consideraram-se as recomendações da Resolução 466/2012 do Conselho Nacional de Saúde no intuito de respeitar os direitos das pessoas envolvidas. A pesquisa iniciou-se após a liberação do Comitê de Ética em Pesquisa com o registro 22026513.4.0000.0053. A fim de garantir a não maleficência, foi mantido o anonimato dos entrevistados, solicitando que eles escolhessem um nome fictício para representá-los no estudo. Com o objetivo de manter a privacidade dos participantes, as entrevistas foram realizadas em locais reservados, na própria clínica hiperbárica, sendo 
que as entrevistas foram previamente negociadas de modo que não interferissem na dinâmica da unidade e respeitassem a disponibilidade dos participantes.

\section{RESULTADOS}

Participaram voluntariamente 12 pessoas do sexo masculino e 2 do sexo feminino. A idade variou entre 30 e 79 anos.

Autodeclararam-se como pardo 6 homens, 4 como brancos, 1 como negro e 1 como amarelo. Entre as mulheres, 1 se intitulou como sendo branca e 1 como parda. Com relação ao grau de instrução, metade dos homens e todas as mulheres possuíam segundo grau completo.

Todos os participantes apresentavam diagnóstico clínico relacionado a algum tipo de ferida cutânea e metade possuía diabetes mellitus como patologia de base. O número de sessões de $\mathrm{OHB}$ realizado pelos entrevistados variou entre 2 a 80.

Após analisar os depoimentos coletados nas entrevistas semiestruturadas, os resultados da aplicação do TALP, os desenhos e as estórias produzidas pelos entrevistados do estudo, emergiram as seguintes categorias: medo e ansiedade; sentimento de prisão e cansaço; felicidade e confiança/ esperança na terapia e em Deus.

\section{Sentimento de medo}

O medo foi representado pelo sentimento de insegurança perante um procedimento novo, medo do desconhecido, medo do maquinário, receio de se sentir mal e não ser socorrido.

Quando eu vi a máquina a primeira vez, fiquei assustado. Parecia assim uma nave, um submarino, que nem eles falam né? [...] Aí eu senti assim um pouco de medo, mas depois acostumei... (Hildo, 59 anos).

[...] Tinha medo de primeira, aquele nervoso, e tal e tal, mas hoje em dia eu estou calmo, nem parece, certo? [...] Não sei..., mas aí, hoje eu estou relaxado, nem me preocupo mais... (Lourival, 52 anos).

O medo é caracterizado por uma perturbação do ânimo, preocupação e distúrbio emocional provocados por ameaça real ou aparente ou pela presença de algo perigoso ou estranho que exerce uma influência negativa no tratamento, afetando desde a frequência do cliente, sua cooperação e resposta orgânica aos enfrentamentos ${ }^{6,7}$.
Observou-se que, após conversa de orientação e esclarecimento sobre o procedimento, o medo foi amenizado. A falta de informação ou a informação excessiva e contraditória é prejudicial, gerando insegurança e ansiedade ${ }^{8}$.

A comunicação entre profissionais e cliente sobre o procedimento, o maquinário e os benefícios contribuem para a diminuição da ansiedade e aumento da autoconfiança na OHB. O conhecimento por meio da comunicação é uma ferramenta para combater o medo'.

Para a confiança se estabelecer é fundamental que o profissional, além de explicar e falar aquilo que acredita, é importante que demonstre por meio de suas ações e condutas um afinamento entre teoria e prática ${ }^{10}$. Essa relação entre profissional e cliente engloba muito mais que a competência técnica, engloba um modo de relacionar-se através da compreensão, do toque, do olhar, do sorriso, do carinho, da fala e do silêncio, condicionado a uma atitude de respeito ao outro. Tratá-lo como ser humano inserido em uma família, com história e cultura próprias, cheios de expectativas, medos e necessidades, permitindo assim vivenciar de forma singular, segura e tranquila o processo saúde-doença $a^{10,11}$.

A escuta de um profissional se torna fundamental para auxiliar o cliente na elaboração desses sentimentos, ouvir suas fantasias, orientá-lo a participar ativamente de seu tratamento, sendo essencial que ele possa falar da doença e de todos os sentimentos que acompanham o diagnóstico e o tratamento ${ }^{11}$.

\section{Sentimento de ansiedade}

Os entrevistados relataram sentir ansiedade pela curiosidade de saber como seria o tratamento, como funcionava o maquinário e a expectativa quanto aos resultados da terapia em suas enfermidades.

[...] Pra mim foi uma supressa uma coisa nova, então fiquei ansioso não conhecia queria saber o que era. (Vinicius, 70 anos).

[...] Eu fiquei assim meio apreensivo, um pouco ansioso, mas eu fiquei assim ansioso pela questão que os outros falavam que melhora o tratamento, que realmente tem resultado, aí fiquei ansioso pra saber né? (Gilvan, 36 anos).

[...] No momento tinha que ver como é que era, não tinha nem noção de como é que era. Tinha que vir aqui ver pra saber como era. Fiquei ansioso. (Lourival, 52 anos).

A ansiedade ocasiona inquietação interna e apreensão, associada ou não a sintomas físicos, os quais são resultados de uma 
expectativa criada pelo cliente. Esses sintomas são testemunhos de uma quebra da homeostase interna que se manifesta entre a percepção de uma necessidade e a sua satisfação ${ }^{12}$.

No teste de associação livre de palavras, após o estímulo com a palavra "hiperbárica", surgiram as respostas: solução do problema, enfermidade e ferida crônica. Para o estímulo "hiperbárica e eu", houve as respostas: cura, mudança, futuro, diferente e ativação. Essas respostas complementam o sentimento de ansiedade, por acreditar que o hoje e o futuro estão relacionados com a cura de suas doenças e com uma recuperação mais rápida, gerando ansiedade em perceber logo a melhora.

O medo, a ansiedade e as angústias do paciente podem agir negativamente em seu processo de adaptação ao setor de $\mathrm{OHB}$, bem como em relação à equipe de saúde e à sua recuperação. Nesse sentido, observar os sentimentos que são externados é fundamental para uma escuta terapêutica, humanizando e resgatando o respeito à vida humana, considerando as circunstâncias sociais, educacionais, psíquicas e emocionais do indivíduo ${ }^{7-9}$.

\section{Sensação de prisão e cansaço}

Os participantes da OHB relataram que as sessões se tornaram um tipo de prisão, pela ausência de liberdade, pela rotina do tratamento e pelo confinamento na câmara que eles deveriam suportar para, enfim, obter sua total liberdade, tanto da terapia quanto das feridas que os acompanhavam há anos (Fig. 1). Em seus desenhos, as imagens eram caracterizadas por pessoas dentro de casa, dentro de um quarto, dentro de círculos fechados, demonstrando a sensação vivenciada de prisão ao tratamento e à doença.

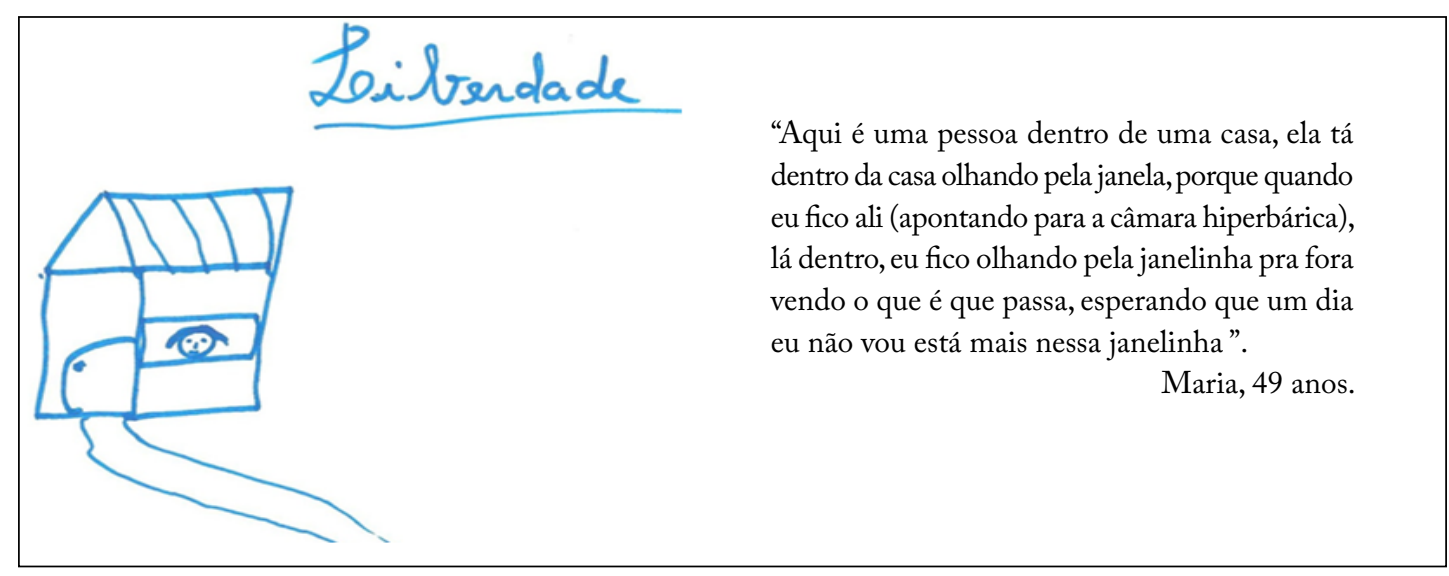

Figura 1. Liberdade.

A forma como a terapia é realizada, diariamente, em horários fixos, dentro de uma câmara, cinco vezes por semana, foi relatada como sendo cansativa:

Eu só acho que demora muito lá dentro, se fosse só uma hora pra mim era melhor, mas é uma e meia... Porque eu estou internada, venho e vou de ambulância particular e ficar esperando é cansativo (Mariana - 62 anos).

Às vezes dá assim um cansaço de ficar assim naquela posição, respirando, respirando, fico com vontade mesmo que dê o horário pra gente terminar, já acostumei mesmo, ter que vir, todos os dias, já é rotina! (Maria 49 anos).

[...] Isso aqui é cansativo, mas em busca de saúde a gente tem que ir atrás, eu estou internado e tenho a hiperbárica, tenho hemodiálise, eu tenho que fazer um sacrifício mesmo, se tem que fazer eu faço sem olhar pra trás (Lourival -52 anos).
A rotina vivenciada por alguns dos clientes que fazem a OHB é extremamente cansativa; além do desgaste diário da terapia, muitos residem em municípios distantes, outros estão internados e/ou fazem outros tipos de tratamento concomitante. O fato de a eficácia dessa terapia estar atrelada à realização diária das sessões faz com que essas pessoas busquem força para prosseguir, almejando a cura no fim da terapia.

No teste de associações livres de palavras com o estímulo "hiperbárica" apareceram as frases: completar e terminar as sessões, muito tempo; e com o estímulo "hiperbárica e eu", as palavras: esperar, liberdade e respirar. As palavras remetem à sensação de que tudo acabe logo, para ter a liberdade de volta e poder "respirar" outra vez.

O tratamento de longa duração em pessoas com doenças crônicas gera mudanças de grande impacto que repercutem em suas vidas e nas vidas de seus familiares e amigos. Há a necessidade de se adaptar à nova realidade, frente ao 
adoecimento crônico, buscando estratégias, como perceber o lado positivo da vida, acreditando na melhoria e desenvolvendo a resiliência no cotidiano ${ }^{13,14}$.

\section{Felicidade}

Após adaptação às sessões de $\mathrm{OHB}$, os depoimentos revelaram sentimento de felicidade, contentamento e bem-estar. Por ser considerada uma terapia nova para os entrevistados, surgem sentimentos de alegria e esperança na recuperação física:

Eu senti uma alegria porque iria resultar de forma positiva na minha saúde, eu me senti mais confiante, mais alegria de viver! [...] Eu fiquei feliz porque eu fui um dos primeiros a fazer esse tratamento aqui pelo SUS. E quando eu cheguei aqui eu senti um acolhimento, um acolhimento que me passou confiança, que poderia ficar curado (Emanuel, 30 anos).

É, me senti feliz, né? Porque eu sei que esse tratamento é um tratamento caro e eu consegui tão rápido pelo SUS, foi Deus mesmo que me ajudou, porque sinceramente pra eu pagar eu não teria condições (Jôjo, 40 anos).
Também foram relatados sentimentos de bem-estar e melhoria de outras patologias segundo as falas e desenhos:

Bem, eu me sinto melhor com o oxigênio, melhor do que quando eu entro. $\mathrm{O}$ oxigênio melhora até essa dor que eu sinto aqui no braço (Val, 64 anos).

Ainda que não tenha totalmente cicatrizado as feridas, outras coisas já voltaram a funcionar normalmente, como por exemplo, eu só tinha metade do pulmão pra respirar, agora eu já consigo respirar com o pulmão todo (Emanuel, 30 anos).

Inclusive me fez muito bem pros rins, meus rins começaram a funcionar muito bem, eu tenho um probleminha renal pequeno, mais depois feito isso eu melhorei... (Vinícius, 70 anos).

Os desenhos retratam pessoas sorrindo, face de alegria, imagens de movimento, livre de muletas, sensação de liberdade e felicidade, acompanhados de discurso com teor positivo e certeza da recuperação (Fig. 2).

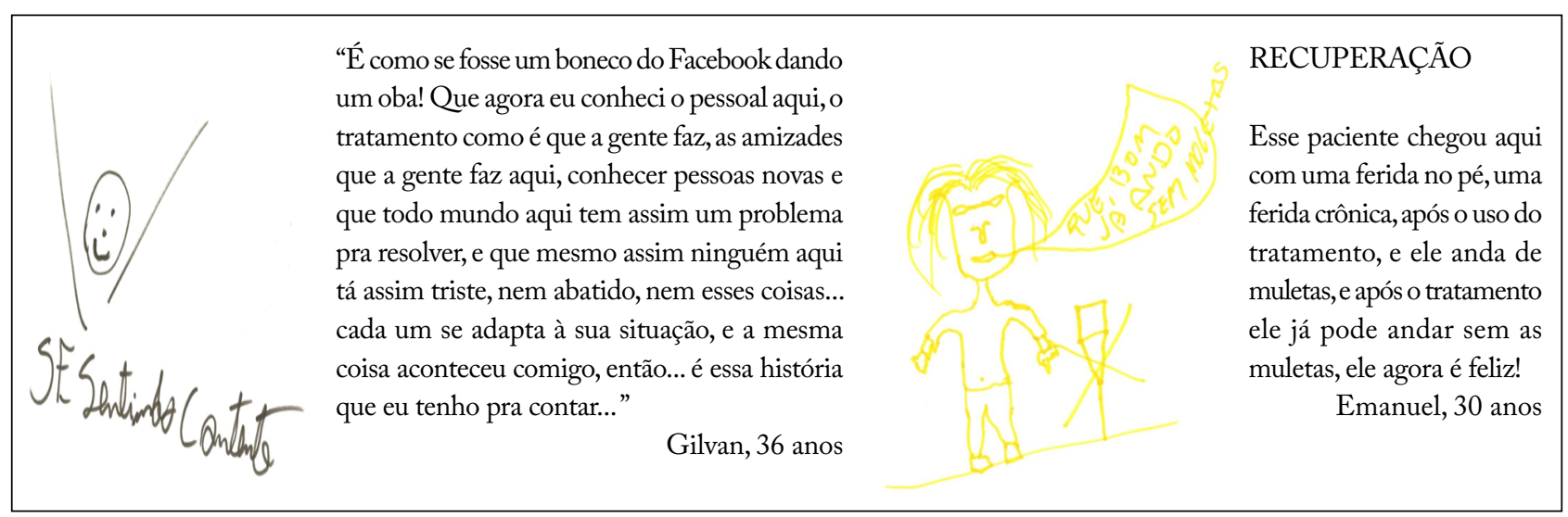

Figura 2. Alegria e recuperação.

$\mathrm{Na}$ associação livre de palavras relacionada à felicidade, com mesmo estímulo "hiperbárica", houve outras respostas: saúde, aconchego, bem-estar e benefícios. Com o estímulo "hiperbárica e eu" apareceram: casamento perfeito, um só, satisfação, bons sentimentos.

Percebe-se que houve uma melhora na vida cotidiana das pessoas, após o início do tratamento. Quando a ferida e a saúde, de uma forma geral, melhoram, consequentemente os relacionamentos afetivos conjugais também se beneficiam8. A qualidade de vida de pessoas com doença crônica tende a melhorar quando há também um sentimento de otimismo, fé e um movimento pessoal em prol da própria recuperação15.
Após a percepção dos clientes que a OHB surte um efeito positivo, há mudanças em sua qualidade de vida, tendo relação positiva com a condição física, vitalidade e relacionamentos sociais, refletindo no bem-estar mental, social e espiritual, proporcionando satisfação e felicidade ${ }^{15}$.

\section{Confiança/esperança}

Essa categoria se subdivide em confiança na terapia e confiança em Deus. Confiança na terapia é representada pela esperança depositada no tratamento, pela expectativa de melhorar e de alcançar a cura e pela sensação de alívio ao se deparar com a OHB: 
Hoje o que eu sinto e que com certeza o que eu pensei lá no início é real, cada dia que passa eu consigo ver os resultados na minha vida. (Manuel 30 anos).

A minha expectativa é essa, de cada dia que eu faço eu vou tá melhor (Toinho, 60 anos).

O desenho da casa retrata a esperança em dias melhores, em novas expectativas para uma vida livre da ferida e de suas repercussões sociais e emocionais (Fig. 3).

A confiança na terapia foi gerada por vários fatores, entre eles a comprovação da eficácia do tratamento, nos resultados obtidos e na relação interpessoal adotada pelos profissionais perante os usuários. $\mathrm{O}$ atendimento acolhedor, o respeito às crenças dos clientes e a explicação de todo o processo da OHB, por meio de uma linguagem simples e de fácil entendimento, contribuíram para a satisfação e confiança.

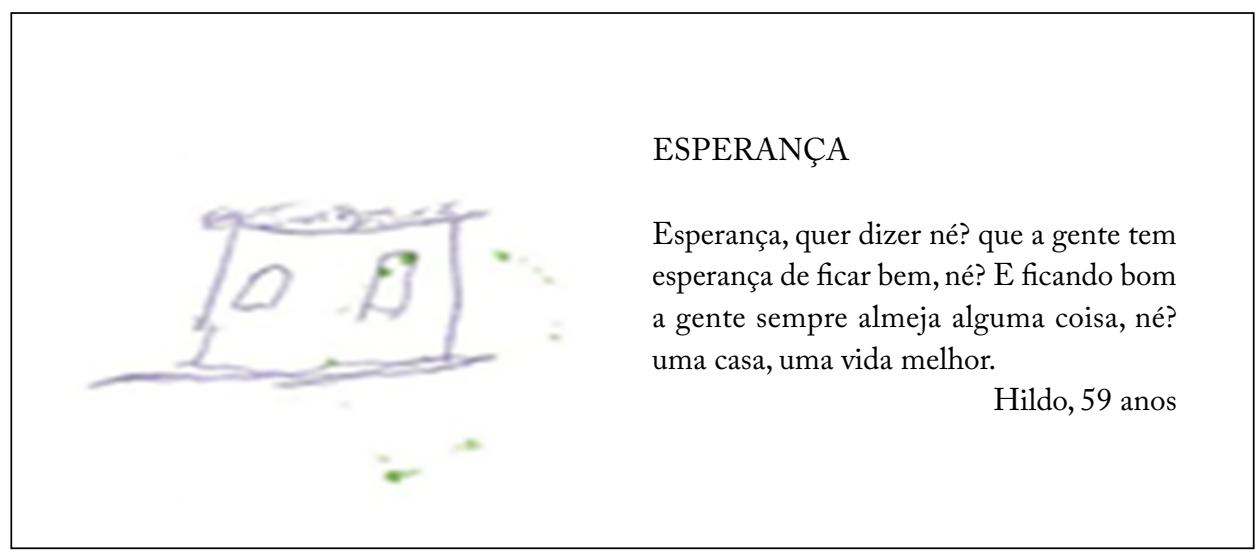

Figura 3. Esperança.

Tratando-se de doença crônica, quando há uma confiança, o indivíduo terá maior disposição para dialogar sobre seus medos e sua visão de mundo, o que facilita na construção de um vínculo muito importante entre quem cuida e o ser cuidado ${ }^{15}$.

$\mathrm{Na}$ associação livre de palavras, o tópico "confiança e esperança” foi o que mais houve resposta aos estímulos. Para a "hiperbárica" apareceu: excelente, qualidade no serviço, eficaz, ótimo, esperança, confiança. Para "hiperbárica e eu": ficar bom, melhora pra mim, benefícios, confiante, coisa boa.

A confiança e a esperança, atribuídas à terapia e a Deus, foram relatadas por quase todos os participantes (Fig. 4). A religiosidade está intrínseca na vida dessas pessoas, independentemente de raça, valores e crenças. Depositam em Deus a oportunidade da $\mathrm{OHB}$ e os benefícios adquiridos.

Eu fiquei muito feliz... Eu agradeço muito a Deus por essa oportunidade, e que graças a Deus eu estou me dando bem (José Lourentino, 67 anos).

É um tratamento novo, que eu muito queria fazer pra melhorar a minha situação, que graças a Deus eu fiz e estou melhorando (Toinho, 60 anos).

Eu tenho esperança, confio em Deus em primeiro lugar, e em segundo na hiperbárica. Eu tenho esperança (Mariana, 62 anos).

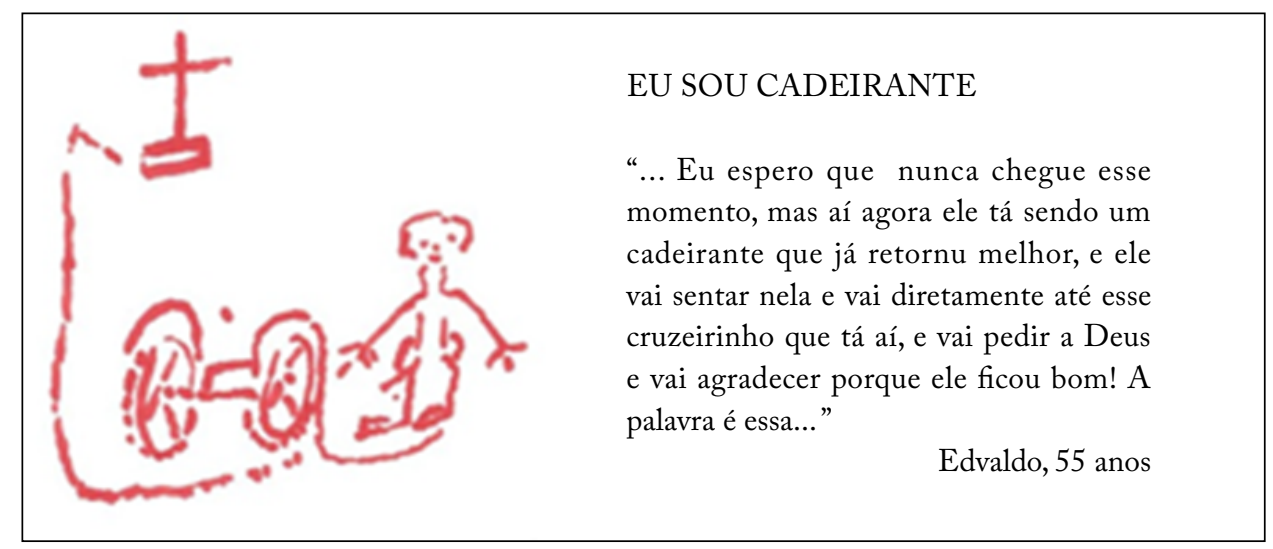

Figura 4. Agradecimento e fé. 
A fé alia-se à esperança e fortalece os indivíduos, que veem em Deus um Ser Supremo que realimenta diariamente o desejo da melhora e da cura, além de reduzir os sentimentos negativos como o medo e a ansiedade ${ }^{16}$.

A imagem representa o desejo de agradecer a Deus, afirmando a religiosidade como algo presente em seu cotidiano, trazendo conforto e esperança.

A associação livre de palavras teve poucas palavras como respostas aos estímulos, entretanto bem explicativas. Para "hiperbárica": muita fé e para "hiperbárica e eu": agradecer e confiança em Deus.

A fé e a confiança representam uma força propulsora que, aliada à crença em Deus, pode propiciar a esperança de cura para a doença16. A fé em Deus atua como elemento positivo no enfrentamento da doença. Ao dar importância à espiritualidade e à religiosidade, há uma melhora na qualidade de vida dessas pessoas com problemas de saúde. A fé, a esperança e o crer em Deus contribuem para a melhora do quadro clínico, emocional e espiritual.

\section{CONCLUSÃO}

Os sentimentos negativos emergidos na pesquisa, como o medo presente nos discursos, que traduzem o desconhecimento da terapia e a falta de informação, e a ansiedade, representada pela expectativa sobre um novo tratamento, o sentimento de prisão associado à câmera hiperbárica toda fechada e o longo período das sessões, foram modificados por sentimentos positivos.

Após as primeiras sessões e principalmente após as orientações e incentivos das profissionais, os sentimentos negativos foram amenizados e cederam espaço para a satisfação por uma terapia em que eles percebiam os resultados, seguida de felicidade em poder voltar ao convívio familiar e social, e tudo isso ancorado no sentimento de esperança e fé.
O estudo possui a limitação por ter um público específico de pessoas com feridas e em uma amostra de apenas 14 pessoas, todavia as técnicas multiparamétricas utilizadas aprofundaram as impressões extraídas dos usuários.

Este estudo contribui para o conhecimento dos sentimentos dos usuários da $\mathrm{OHB}$, principalmente aqueles que possuem feridas crônicas e complexas que, a cada dia, vêm sendo tratadas por meio desse método. Nesse sentido, amplia-se o conhecimento sobre essa clientela, podendo o enfermeiro, estomaterapeuta ou não, prestar uma assistência diferenciada a essas pessoas.

\section{AGRADECIMENTOS}

Agradecemos às pessoas com úlceras de perna, usuários da Hiperbárica Feira de Santana que partilharam suas experiências e possibilitaram este estudo.

\section{FINANCIAMENTO}

Não houve financiamento.

\section{CONTRIBUIÇÃO DOS AUTORES}

Conceitualização, Machado MSC e Carvalho ESS; Metodologia, Machado MSC e Carvalho ESS; Investigação, Machado MSC; Carvalho ESS e Costa CSS; Redação Primeira versão, Machado MSC; Carvalho ESS; Costa CSS e Paranhos RFB; Redação - Revisão \& Edição, Machado MSC; Carvalho ESS; Costa CSS e Paranhos RFB; Supervisão, Machado MSC; Carvalho ESS; Costa CSS e Paranhos RFB.

\section{REFERÊNCIAS}

1. Chantre C, Foucher S, Le Hot H, Lefort H, Blatteau J-É. Hyperbaric oxygen therapy, a little-known discipline. Rev Infirm. 2018;67(242):14-5. https://doi.org/10.1016/j. revinf.2018.03.012

2. Mathieu D, Marroni A, Kot J. Tenth European Consensus Conference on Hyperbaric Medicine: recommendations for accepted and non-accepted clinical indications and practice of hyperbaric oxygen treatment. Diving Hyperb Med. 2017;47(1):24-32.

3. Minayo MCS. Análise qualitativa: teoria, passos e fidedignidade. Ciênc Saúde Coletiva. 2012;17(3):621-6. https://doi.org/10.1590/S1413-81232012000300007 
4. Pinto ER. Conceitos fundamentais dos métodos projetivos. Ágora. 2014;17(1):135-53. https://doi.org/10.1590/S151614982014000100009

5. Coutinho MPL, Nóbrega SM, Catão MFM. Contribuições teórico-metodológicas acerca do uso dos instrumentos projetivos no campo das representações sociais. In: Coutinho MPL, Lima AS, Oliveira FB, Fortunato ML, editores. Representações sociais: abordagem interdisciplinar. João Pessoa: Editora Universitária UFPB; 2003. p.50-66.

6. Perdigon AGC, Strasser G. Dying process and nursing: a relational approach. Theoretical reflections on assistance dealing with death. Physis. 2015;25(2):485-500. https://doi. org/10.1590/S0103-73312015000200009

7. Cruickshank S, Steel E, Fenlon D, Armes J, Banks E, Humphris G. Specialist breast cancer nurses' views on implementing a fear of cancer recurrence intervention in practice: a mixed methods study. Support Care Cancer. 2020;28(1):201-10. https://doi.org/10.1007/s00520-019-04762-9

8. Félix RA, Santos RA. Assistência de enfermagem ao paciente submetido à oxigenoterapia hiperbárica. Rev Transformar. 2017;2017:140-51.

9. Hartley BR, Hong C, Elowutz E. Communication in Neurosurgery-The Tower of Babel. World Neurosurg. 2020;133:457-65. https://doi.org/10.1016/j. wneu.2019.08.134

10. Souza NS, Silva CC, Chagas FRC, Silva NF, Silva SV, Souza TSB. Repercussions of care technologies in intensive care units. J Nurs UFPE online. 2018;12(10):2864-72. https://doi. org/10.5205/1981-8963-v12i10a236449p2864-2872-2018
11. Henriques LVL, Dourado MARF, Melo RCCP, Tanaka LH. Implementation of the Humanitude Care Methodology: contribution to the quality of health care. Rev Latino-Am Enfermagem. 2019;27:e3123. https://doi.org/10.1590/15188345.2430-3123

12. Chen $\mathrm{H}$, Cai $\mathrm{C}$, Xie J. The effect of an intensive patients' education program on anxiety, depression and patient global assessment in diabetic foot ulcer patients with Wagner grade 1/2: A randomized, controlled study. Medicine. 2020;99(6):e18480. https://doi.org/10.1097/ MD.0000000000018480

13. Silva GO, Peixoto LCP, Souza DA, Santos ALS, Aguiar ACSA. Repercussions of chronic diseases on the mental health of elderly people. I Nurs UFPE online. 2018;12(11):2923-32. https://doi.org/10.5205/1981-8963v12i11a234540p2923-2932-2018

14. Santos LA, Oliveira PP, Silveira EAA, Gesteira ECR, Fonseca $D F$, Rodrigues AB. The resilience process in family caregivers of people with malignant neoplasia. Esc Anna Nery. 2019; (3):e20190023. https://doi.org/10.1590/2177-9465ean-2019-0023

15. Menezes RR, Kameo SY, Valença TS, Mocó GAA, Santos JMJ. Quality of life related to health and spirituality in individuals with cancer. Rev Bras Cancerol. 2018;64(1):9-17.

16. Kunz JA, Conde CR, Lemos TMR, Barros AES, Ferreira MLSM. A religiosidade e espiritualidade de mulheres com câncer de mama submetidas a tratamento cirúrgico. Rev Enferm Atual In Derme. 2018;86(24). 